\title{
Review Article \\ Survey of Energy-Efficient Techniques for the Cloud-Integrated Sensor Network
}

\author{
Kalyan Das $\mathbb{D}^{1,2}$ Satyabrata Das, ${ }^{2}$ Rabi Kumar Darji, ${ }^{1}$ and Ananya Mishra ${ }^{1}$ \\ ${ }^{1}$ Sambalpur University, SUIIT, Burla, Odisha, India \\ ${ }^{2}$ Veer Surendra Sai University of Technology, Burla, Odisha, India \\ Correspondence should be addressed to Kalyan Das; kalyandas1983@gmail.com
}

Received 6 June 2017; Revised 9 October 2017; Accepted 26 November 2017; Published 7 February 2018

Academic Editor: Fanli Meng

Copyright (c) 2018 Kalyan Das et al. This is an open access article distributed under the Creative Commons Attribution License, which permits unrestricted use, distribution, and reproduction in any medium, provided the original work is properly cited.

\begin{abstract}
The sensor cloud is a combination of cloud computing with a wireless sensor network (WSN) which provides an easy to scale and efficient computing infrastructure for real-time application. A sensor cloud should be energy efficient as the life of the battery in the sensor is limited and there is a huge consumption of energy in the data centre in running the servers to provide storage. In this paper, we have classified energy-efficient techniques for sensor cloud into different categories and analyzed each technology by using various parameters. Usage percentage of each parameter for every technology is calculated and for all technologies on average is also calculated. From our analysis, we found that most of the energy-efficient techniques ignore quality of service (QoS) parameters, scalability, and network lifetime. Multiparameter optimization including other QoS parameters along with energy may be the future direction of research. Our study will be helpful for researchers to get information regarding current methods used for an energy-efficient sensor cloud and also to build advanced systems in the future.
\end{abstract}

\section{Introduction}

Sensors are used for various applications at present, a number of sensors can combine to form a WSN. Every sensor can communicate with each other through a wireless communication medium using a transceiver to perform specific applications. Each sensor operates on a battery with limited lifetime, so building an energy efficient network model, to maximize network lifetime, is a research challenge. In cloud computing technology, the end user gets a platform, infrastructure, and software support in rent from the cloud service provider. A sensor cloud is an integration of WSN with cloud computing for providing access of sensor to the user through cloud computing and to strengthen the performance of cloud computing applications or sensor networks, by applying the powerful cloud to store, share, and process the collected data by a mixture of sensors. End users do not have to worry about the detail configuration, location, and types of sensor in the cloud sensor infrastructure which virtualizes many physical sensors into virtual sensors. Virtual sensors automatically group to provide services in response to a request from the user. The services like interface for user registration or removing the physical sensor and monitoring and controlling the virtual sensor are provided by the sensor-cloud infrastructure. The sensor cloud uses the virtualization technique for the wireless sensors and gives sensing as a service to users as users use this service on demand from the sensor cloud. The owners of the sensor own the p sensors, which allow the user to use those physical sensors for a rental fee through a sensor-cloud infrastructure. There is a different owner for each WSN. The owner of the sensor registers the physical sensors to the sensor-cloud infrastructure with their properties and deletes the registration once the owner does not have an interest to share its physical sensor. A sensor-cloud infrastructure is proposed by which a physical sensor is managed on a computing infrastructure [1], WSN nodes are connected to a cloud infrastructure [2], and also in which WSN nodes transmit data to the cloud which stores, processes, analyzes, and sends it to various clients [3]. A survey of various works in sensor-cloud infrastructure is proposed which gives 
current challenges to current existing technology solutions and also mentions the future direction of research [4]. A review of the current work for designing energy-efficient sensing is proposed based on location information in mobile cloud computing environment [5]. A review of recent works for an energy estimation model is proposed for various mobile nodes, and a survey is made on saving of energy during transmission, which focuses the future direction of research [6]. The sensor cloud should be energy efficient as the life of the battery of sensor is limited, and there is a huge requirement of energy in data centres for running servers and providing storage. A comparative study of different architectures of an energy-efficient sensor cloud which compares the layers, main components, and the applications is given in Table 1.

In this paper, we survey efficient techniques for the sensor-cloud environment. To begin with, Section 2 discusses the classifications of energy-efficient techniques for the sensor cloud. Section 3 explains the parameters used for the energy-efficient sensor-cloud techniques. Section 4 discusses the relative analysis of parameters. Finally, Section 5 provides the conclusion of the paper with final remarks.

\section{Classification of Energy-Efficient Techniques for the Sensor Cloud}

In our review, we have classified energy-efficient techniques for the sensor cloud into six categories including scheduling techniques, sensing techniques, data transmission techniques, advanced system designing, data processing, and load balancing techniques as shown in Figure 1.

2.1. Scheduling Techniques. Energy-efficient and delay-aware computing system (E2DAWCS) is used to reduce the consumption of power by controlling both network connectivity and sleep scheduling within admissible delay [7]. Data aggregation, physical sensor scheduling, and low-power listening techniques are used to minimize the sending of sensed packets for transmission. As a result, energy consumption is further minimized [8]. Time division multiple accesses(TDMA-) based scheduling for fine granularity tasks is used for energy saving, providing less response time and high throughput [9]. Optimizing scheduling of transmission and adjustment of the clock frequency technique is used to minimize the consumption of energy for mobile resource constraint device [10]. A task execution framework is proposed which selects the favorable sensors for less energy consumption, optimizing concurrent task execution by removing redundancy [11]. Clustered multichannel scheduling scheme accumulates data concurrently from multiple sections and sends it to the sink while reducing power consumption and yielding high throughput and delivery ratio [12]. Real-time thing allocation heuristic algorithm is used to minimize the total energy consumption using the QoS-aware selection of service problem for the IoT-based cloud platforms [13]. A scheduling technique is proposed based on dynamic duty cycle which minimizes energy consumption and cost in the sensor cloud [14]. The benefits, methods used, and drawbacks of various research studies for energy-efficient scheduling techniques for the sensor cloud are given in Table 2.

2.2. Sensing Techniques. Cloud sensing and optimization of query processing techniques are used so that energy overhead is reduced and improves scalability [15]. Location, context, and activity-aware selective sensing is used to reduce the consumption of energy, storage, and data processing requirements [16]. The cloud-offloaded global positioning system (CO-GPS) which provides sensing devices to assure duty cycle of the GPS receiver device and logging the millisecond raw data from the GPS signal for processing technique is helpful to conserve energy [17]. Collaborative sensing and aggregation of information using trusted middleware provide energy saving [18]. Sensing as a service mechanism provides energy efficiency, supports multiple applications in a flexible and secure loading on various platforms, and also supports the incentive mechanism [19]. The benefits, methods used, and drawbacks of various current research papers for energy-efficient sensing techniques for the sensor cloud are shown in Table 3.

2.3. Data Transmission Techniques. The optimal decision rule method is used which selects the best bridge node to reduce the transmission energy consumption of every node [20]. Customizable sensor information system model is used to modify data transmission and frequency of data collection to make it energy efficient, and this approach also reduces $\mathrm{CO}_{2}$ emissions [21]. A framework for wirelessly powered based on mobile computing under the constraints of deadlines and energy harvesting is proposed to minimize the energy consumption of local computing and maximizing the energy saving for offloading computing [22]. The sensor-cloud integrated platform is used to perform pushpull communication among the three layers of the system architecture for energy-efficient data transmission. This approach uses lesser bandwidth while collecting a high amount of data from the user [23]. The Senud compression algorithm which is used to reduce replicated data as a result of transmission energy consumption is minimized, and this method is also suitable for high volume numerical data [24]. The benefits, methods used, and drawbacks of various recent papers for energy-efficient data transmission techniques for the sensor cloud are given in Table 4 .

2.4. Advanced System Designing. A cloud orchestration approach which supports dynamic workflow among service components is used to coordinate services based on cloud computing, as a result, it provides energy efficiency [25]. A data prediction model is used so that energy consumption is minimized in a sensor-cloud infrastructure [26]. A selfmanaged sensor-cloud technique is used to automatically carry out energy management, management of the event, aggregation of data, and management of connection and to handle critical applications. This approach also provides fast response in case of an emergency [27]. A cloud architecture uses a publishing or subscribing middleware which manages the sensors. It also removes the redundant sensors and minimizes energy consumption [28]. An architecture proposes balancing of energy efficiency and data quality. 
TABLE 1: A comparative study of different architectures of the energy-efficient sensor cloud.

\begin{tabular}{|c|c|c|c|}
\hline References & Layers/levels & Main components & Applications \\
\hline [8] & $\begin{array}{l}\text { Application, sensor-cloud, } \\
\text { physical WSNs }\end{array}$ & $\begin{array}{l}\text { Sensor-cloud sensing as a service, request aggregator, } \\
\text { and virtual and physical sensor manager }\end{array}$ & $\begin{array}{l}\text { Generalized for any type } \\
\text { of applications }\end{array}$ \\
\hline [9] & $\begin{array}{l}\text { Client centric, middleware, } \\
\text { sensor centric }\end{array}$ & $\begin{array}{l}\text { User membership management, provision management, } \\
\text { service catalogue, billing management, } \\
\text { data collection, and WSN maintenance }\end{array}$ & $\begin{array}{l}\text { Support multiple } \\
\text { application environments }\end{array}$ \\
\hline [11] & Application, internet, sensor network & $\begin{array}{l}\text { User smartphone, internet, server, gateways, } \\
\text { resources nodes, monitor, and camera }\end{array}$ & $\begin{array}{l}\text { Framework for task } \\
\text { execution }\end{array}$ \\
\hline [14] & Sensor cloud, on-field sensor network & $\begin{array}{l}\text { Sensor cloud, on-field sensor network, soil moisture } \\
\text { sensors, gateway nodes, and terrestrial sensors }\end{array}$ & $\begin{array}{l}\text { Specialized in agricultural } \\
\text { field }\end{array}$ \\
\hline [16] & $\begin{array}{l}\text { Global sensor network (GSN), mobile } \\
\text { sensor data engine, and devices }\end{array}$ & $\begin{array}{l}\text { Context aware mobile sensor data engine, activity-aware } \\
\text { module, location aware module, and GSN middleware }\end{array}$ & $\begin{array}{l}\text { Environment monitoring } \\
\text { and health services }\end{array}$ \\
\hline [18] & Sensor, middleware, application, cloud & $\begin{array}{l}\text { Mobile devices embedded with sensor, } \\
\text { middleware, applications, and cloud server }\end{array}$ & Mobile sensing \\
\hline [19] & Cloud user, cloud systems, sensing & $\begin{array}{l}\text { Sensing server, load balancer, web server, } \\
\text { and database server }\end{array}$ & Sensing service \\
\hline [20] & End user, sensor cloud, physical sensor & $\begin{array}{l}\text { Sensor owners, sensor cloud, access point, } \\
\text { virtualization, and processing }\end{array}$ & $\begin{array}{l}\text { Environment monitoring } \\
\text { and target tracking }\end{array}$ \\
\hline [21] & Application, virtual, physical & $\begin{array}{c}\text { Data quality (DQ) services catalogue, DQ monitor, } \\
\text { and DQ aware adaptation }\end{array}$ & $\begin{array}{l}\text { Environmental } \\
\text { management }\end{array}$ \\
\hline [23] & Sensor layer, edge layer, cloud layer & $\begin{array}{l}\text { Sensor nodes, virtual sensor nodes, and cloud } \\
\text { applications }\end{array}$ & $\begin{array}{l}\text { Physiological and } \\
\text { environmental } \\
\text { monitoring }\end{array}$ \\
\hline$[24]$ & $\begin{array}{l}\text { Service, storage, data, activities, } \\
\text { transportation, physical }\end{array}$ & $\begin{array}{l}\text { Web service, storage allocation, security } \\
\text { management, data analyzing, filtering \& } \\
\text { reconstruction units, response monitoring, service } \\
\text { monitoring, router, and physical or virtual sensor group }\end{array}$ & $\begin{array}{l}\text { Numerical data } \\
\text { compression }\end{array}$ \\
\hline$[25]$ & Physical, internet of things (IoT) & $\begin{array}{c}\text { Data processor, participating devices, big data storage, } \\
\text { control and wisdom box, decision enhancer, } \\
\text { and knowledge graph }\end{array}$ & Smartphones in the IoT \\
\hline$[28]$ & $\begin{array}{l}\text { Application, cloud system, middleware, } \\
\text { physical device }\end{array}$ & $\begin{array}{l}\text { Quality of service broker, decision-making } \\
\text { engine, and configuration module }\end{array}$ & $\begin{array}{l}\text { Urban crowd sensing and } \\
\text { data analysis }\end{array}$ \\
\hline [29] & $\begin{array}{l}\text { Consumer, cloud services, controller, } \\
\text { producer }\end{array}$ & $\begin{array}{l}\text { Customizable motes, network controllers, } \\
\text { DQ energy optimizer cloud services, and } \\
\text { cloud service customer interface }\end{array}$ & $\begin{array}{l}\text { Producer consumer data } \\
\text { flow }\end{array}$ \\
\hline [30] & User, server, mobile client & $\begin{array}{l}\text { Network, server, database, task information, } \\
\text { mobile client, and users }\end{array}$ & Mobile computing system \\
\hline [31] & Internet, virtual sink, sensor zone & $\begin{array}{l}\text { Internet, sink point/cloud nodes, } \\
\text { sensor zone, and scheduler }\end{array}$ & $\begin{array}{l}\text { Distributed storing and } \\
\text { processing data }\end{array}$ \\
\hline [32] & Cloud, edge and beneath & Gateway, sensor, and cloud systems & Monitoring environment \\
\hline [33] & $\begin{array}{l}\text { Applications, smartphone access layer, } \\
\text { smartphones }\end{array}$ & $\begin{array}{l}\text { Smart phone resource monitoring, } \\
\text { query registry, query evaluation engine, } \\
\text { and rule mining engine }\end{array}$ & Query evaluation \\
\hline$[34]$ & $\begin{array}{l}\text { Sensor layer, coordinator layer, } \\
\text { supervision layer }\end{array}$ & $\begin{array}{l}\text { Sensors, XBee platform, REST web services, } \\
\text { firewall, web app, and iPhone app }\end{array}$ & $\begin{array}{l}\text { Smart homes, healthcare, } \\
\text { vehicular networks }\end{array}$ \\
\hline$[36]$ & Application, sensor, physical & $\begin{array}{l}\text { Crowd-sourced route database and mobile } \\
\text { device with GPS-enabled and altitude sensors }\end{array}$ & Altitude matching \\
\hline [38] & $\begin{array}{l}\text { Remote clouds, camera sensor, local } \\
\text { cloud access point, scalar sensor }\end{array}$ & $\begin{array}{l}\text { Sensor, virtual machine, camera selector, camera } \\
\text { controller, coverage optimizer, and cloudlet status }\end{array}$ & $\begin{array}{l}\text { Complex event } \\
\text { monitoring }\end{array}$ \\
\hline
\end{tabular}

It manages the trade-off between the quality of data reception and energy consumption [29]. Green energy mobile cloud (GEMCloud) system for distributed computing to support complex, parallel jobs and saves energy consumption by 55 to $98 \%$ with many mobile devices that works cooperatively [30]. The architecture, based on cloud computing, for WSN where the virtual sink is used for collection of sensed information and there are many sink points to process the sensed data, in a distributed manner to reduce energy consumption, transmission error, delay, and the number of end to end hops [31]. Optimal push/ pull envelope with lazy sampling technique is used to 


\begin{tabular}{|c|c|c|}
\hline \\
\hline & \multirow{5}{*}{$\begin{array}{l}\text { Scheduling } \\
\text { techniques }\end{array}$} & Sleep scheduling \\
\hline & & Physical sensor scheduling \\
\hline & & TDMA-based scheduling \\
\hline & & Scheduling data transmission \\
\hline & & Concurrent task execution algorithm \\
\hline & \multirow{7}{*}{$\begin{array}{l}\text { Sensing } \\
\text { techniques }\end{array}$} & Multichannel scheduling scheme \\
\hline & & Real-time thing allocation heuristic \\
\hline & & Dynamic duty cycle-based scheduling \\
\hline & & Cloud-based mobile sensing \\
\hline & & Selective sensing using sensor data \\
\hline & & GPS sensing \\
\hline & & Collaborative sensing \& aggregation \\
\hline & \multirow{4}{*}{$\begin{array}{l}\text { Data transmission } \\
\text { techniques }\end{array}$} & Mobile phone sensing \\
\hline \multirow[t]{21}{*}{$\begin{array}{l}\text { Energy-efficient } \\
\text { techniques }\end{array}$} & & $\begin{array}{l}\text { Optimal decision rule for bridge node } \\
\text { selection for energy efficient data transmission }\end{array}$ \\
\hline & & $\begin{array}{l}\text { Modification of frequency of collection } \\
\& \text { transmission of data }\end{array}$ \\
\hline & & Wireless energy transfer \\
\hline & \multirow{8}{*}{$\begin{array}{l}\text { Advanced system } \\
\text { designing }\end{array}$} & Pull-push communication among cloud \\
\hline & & Compression \& transmission \\
\hline & & Cloud orchestration approach \\
\hline & & Data prediction model \\
\hline & & Self-managed sensor cloud technique \\
\hline & & Cloud-based publish or subscribe middleware \\
\hline & & Architecture for balancing energy with data quality \\
\hline & & GEMCloud system for complex \& parallel jobs \\
\hline & \multirow{6}{*}{ Data processing } & Architecture based on virtual sink \\
\hline & & $\begin{array}{l}\text { Push/pull envelope architecture with lazy sampling } \\
\text { technique }\end{array}$ \\
\hline & & Query management and optimization \\
\hline & & Avoiding network disruption \& loss of data \\
\hline & & Storage \& retrieval of big data \\
\hline & & Route-matching approach with altitude data \\
\hline & & Node selection strategy \\
\hline & \multirow{2}{*}{$\begin{array}{l}\text { Load balancing } \\
\text { techniques }\end{array}$} & Selection of service access point scheme \\
\hline & & Load balancing using hybrid ant colony optimization \\
\hline & & Load balancing routing strategy \\
\hline
\end{tabular}

Figure 1: Classification of energy-efficient techniques for the sensor cloud.

minimize energy consumption [32]. The algorithms used, benefits, and drawbacks of various current research papers for energy-efficient advanced system designing for the sensor cloud are given in Table 5.

2.5. Data Processing. Cloud-based query management and optimization techniques are used to lower the cost involved in sensing, reduces the maximum uncertainty, and propagates the query-evaluated result intelligently to reduce energy consumption [33]. A framework of integrated WSN and cloud is proposed which avoids network disruption, reduces loss of data, and increases network lifetime. Using this technique, sensor data can be accessed anywhere at any time with the help of the internet [34]. An algorithm is proposed by 
TABLE 2: Energy-efficient scheduling techniques for the sensor cloud.

\begin{tabular}{|c|c|c|c|c|}
\hline References & Algorithm/methods & Problem discussed & Benefit/achievement & Drawback/limitation \\
\hline [7] & E2DAWCS & $\begin{array}{l}\text { Network connectivity and } \\
\text { sleep scheduling }\end{array}$ & Less energy consumption & $\begin{array}{c}\text { Does not support scalability } \\
\text { and QoS }\end{array}$ \\
\hline [8] & $\begin{array}{l}\text { Scheduling, data aggregation, } \\
\text { and low-power listening }\end{array}$ & $\begin{array}{l}\text { Minimizing the sensed } \\
\text { packets for transmission }\end{array}$ & $\begin{array}{l}\text { Energy efficient, reliable, less } \\
\text { latency, and scalable }\end{array}$ & $\begin{array}{l}\text { On demand requests for } \\
\text { applications is yet to be } \\
\text { analyzed }\end{array}$ \\
\hline [9] & TDMA-based scheduling & $\begin{array}{l}\text { Scheduling for fine } \\
\text { granularity tasks }\end{array}$ & $\begin{array}{l}\text { Provides less response time, high } \\
\text { throughput, and energy efficient }\end{array}$ & $\begin{array}{l}\text { Scalability and reliability } \\
\text { are yet to be addressed }\end{array}$ \\
\hline$[10]$ & $\begin{array}{l}\text { Optimize scheduling of } \\
\text { transmission }\end{array}$ & $\begin{array}{l}\text { Dynamic adjustment of } \\
\text { clock frequency }\end{array}$ & Minimizes the energy consumption & $\begin{array}{c}\text { Does not support real-time } \\
\text { application }\end{array}$ \\
\hline [11] & Task execution & $\begin{array}{l}\text { Selecting the favorable } \\
\text { sensors }\end{array}$ & Energy efficient & $\begin{array}{c}\text { Does not support load } \\
\text { balancing }\end{array}$ \\
\hline [12] & $\begin{array}{l}\text { Clustered multichannel } \\
\text { scheduling }\end{array}$ & $\begin{array}{l}\text { Multichannel hierarchical } \\
\text { scheduling }\end{array}$ & $\begin{array}{l}\text { Provides high throughput, high } \\
\text { delivery ratio, and energy efficient }\end{array}$ & $\begin{array}{l}\text { Real-time implementation } \\
\text { is yet to be done }\end{array}$ \\
\hline [13] & $\begin{array}{l}\text { Real-time thing allocation } \\
\text { heuristic }\end{array}$ & $\begin{array}{l}\text { QoS aware selection of } \\
\text { service }\end{array}$ & Less energy consumption & $\begin{array}{l}\text { Sporadic service is yet } \\
\text { to be supported }\end{array}$ \\
\hline [14] & $\begin{array}{c}\text { Dynamic duty cycle } \\
\text { scheduling }\end{array}$ & $\begin{array}{l}\text { Scheduling to improve } \\
\text { efficiency in WSN }\end{array}$ & $\begin{array}{l}\text { Minimized cost and energy } \\
\text { consumption }\end{array}$ & $\begin{array}{l}\text { Does not support real-time } \\
\text { cloud applications }\end{array}$ \\
\hline
\end{tabular}

TABle 3: Energy-efficient sensing techniques for the sensor cloud.

\begin{tabular}{|c|c|c|c|c|}
\hline References & Algorithm/method & Problem discussed & Benefit/achievement & Drawback/limitation \\
\hline [15] & $\begin{array}{l}\text { Cloud sensing and } \\
\text { optimization of query } \\
\text { processing }\end{array}$ & $\begin{array}{l}\text { Coordinate sensing and } \\
\text { executing tasks }\end{array}$ & Energy efficient and scalable & $\begin{array}{l}\text { Testing of working version } \\
\text { is yet to be done }\end{array}$ \\
\hline [16] & Selectively sensing & $\begin{array}{l}\text { Location and context and } \\
\text { activity based }\end{array}$ & $\begin{array}{c}\text { Reduced energy consumption, } \\
\text { storage, and data processing } \\
\text { requirement }\end{array}$ & Privacy is not preserved \\
\hline [17] & CO-GPS & $\begin{array}{l}\text { Sensing devices to assure duty } \\
\text { cycle of the GPS receiver device }\end{array}$ & Energy efficient & $\begin{array}{l}\text { Location accuracy and } \\
\text { processing speed are yet to } \\
\text { be analyzed }\end{array}$ \\
\hline [18] & Collaborative sensing & Information aggregation & Utilization of energy is improved & $\begin{array}{l}\text { Not scalable and privacy } \\
\text { is not preserved }\end{array}$ \\
\hline [19] & Sensing as a service & $\begin{array}{l}\text { Multiple applications and } \\
\text { incentive mechanism }\end{array}$ & $\begin{array}{c}\text { Energy efficient, flexible, and } \\
\text { provides secure loading on various } \\
\text { platforms }\end{array}$ & $\begin{array}{l}\text { Not scalable and more } \\
\text { costly }\end{array}$ \\
\hline
\end{tabular}

TABle 4: Energy-efficient data transmission techniques for the sensor cloud.

\begin{tabular}{|c|c|c|c|c|}
\hline References & Algorithm/method & Problem discussed & Benefit/achievement & Drawback/limitation \\
\hline$[20]$ & Optimal decision rule & $\begin{array}{l}\text { Selection of the bridge node in the } \\
\text { virtual sensor network }\end{array}$ & $\begin{array}{l}\text { Reduces the energy consumption of } \\
\text { every node }\end{array}$ & $\begin{array}{l}\text { Heterogeneity and node } \\
\text { mobility are yet to be } \\
\text { considered }\end{array}$ \\
\hline [21] & $\begin{array}{l}\text { Customizable sensor } \\
\text { information system }\end{array}$ & $\begin{array}{l}\text { To modify the transmission of data } \\
\text { and frequency of data collection }\end{array}$ & $\begin{array}{l}\text { Energy efficient and reduces the } \\
\text { emission of } \mathrm{CO}_{2}\end{array}$ & Not scalable \\
\hline$[22]$ & $\begin{array}{l}\text { Wireless energy } \\
\text { transfer }\end{array}$ & $\begin{array}{c}\text { Energy harvesting and deadline } \\
\text { constraints }\end{array}$ & Less energy consumption & $\begin{array}{l}\text { Does not support } \\
\text { multitasking }\end{array}$ \\
\hline [23] & $\begin{array}{l}\text { Pull-push } \\
\text { communication }\end{array}$ & Sensor and cloud integration & $\begin{array}{l}\text { Less bandwidth consumption, energy } \\
\text { efficient, and collects more data }\end{array}$ & Does not support QoS \\
\hline$[24]$ & $\begin{array}{l}\text { Compression } \\
\text { algorithm }\end{array}$ & Reduction of replicated data & Transmission energy is minimized & $\begin{array}{l}\text { Data prediction is yet } \\
\text { to be implemented }\end{array}$ \\
\hline
\end{tabular}


TABLE 5: Energy-efficient advanced system designing for the sensor cloud.

\begin{tabular}{|c|c|c|c|c|}
\hline References & Algorithm/method & Problem discussed & Benefit/achievement & Drawback/limitation \\
\hline [25] & $\begin{array}{l}\text { Cloud orchestration } \\
\text { approach }\end{array}$ & $\begin{array}{c}\text { Dynamic workflow and coordination } \\
\text { of services }\end{array}$ & Flexible and energy efficient & $\begin{array}{c}\text { Data mining and filtering } \\
\text { techniques are yet to be } \\
\text { analyzed }\end{array}$ \\
\hline$[26]$ & Data prediction & $\begin{array}{c}\text { To minimize energy consumption } \\
\text { using data prediction }\end{array}$ & $\begin{array}{l}\text { Energy efficient and provides } \\
\text { less error rate }\end{array}$ & $\begin{array}{l}\text { Does not support } \\
\text { scalability and QoS }\end{array}$ \\
\hline [27] & Self-managed sensor cloud & Automation and aggregation of data & $\begin{array}{l}\text { Energy efficient and fast } \\
\text { response in case of an } \\
\text { emergency }\end{array}$ & $\begin{array}{l}\text { Hardware testing is yet to } \\
\text { be implemented }\end{array}$ \\
\hline [28] & $\begin{array}{l}\text { Publish or subscribe } \\
\text { middleware }\end{array}$ & $\begin{array}{l}\text { Satisfying sensing and removing } \\
\text { redundant sensors }\end{array}$ & $\begin{array}{l}\text { Reduction in consumption of } \\
\text { energy by } 40 \% \text { to } 80 \%\end{array}$ & $\begin{array}{l}\text { Data analysis is not } \\
\text { performed }\end{array}$ \\
\hline [29] & $\begin{array}{c}\text { Balancing energy } \\
\text { consumption with respect } \\
\text { to data quality }\end{array}$ & $\begin{array}{l}\text { Managing the quality of the } \\
\text { reception data while saving energy }\end{array}$ & $\begin{array}{l}\text { Less energy consumption and } \\
\text { QoS is maintained }\end{array}$ & Not scalable \\
\hline$[30]$ & GEMCloud & $\begin{array}{c}\text { To support complex and parallel jobs } \\
\text { in the distributed computing } \\
\text { environment }\end{array}$ & Energy efficient & $\begin{array}{l}\text { Security is yet to be } \\
\text { analyzed }\end{array}$ \\
\hline$[31]$ & $\begin{array}{l}\text { Architecture based on } \\
\text { virtual sink }\end{array}$ & $\begin{array}{l}\text { Processing and storing the } \\
\text { information through many sinks }\end{array}$ & $\begin{array}{c}\text { Energy efficient, less } \\
\text { transmission error, and less } \\
\text { end to end delay }\end{array}$ & Not scalable \\
\hline [32] & $\begin{array}{l}\text { Push/pull envelope with } \\
\text { lazy sampling }\end{array}$ & $\begin{array}{c}\text { Optimal sampling for transmitting } \\
\text { the sensor data between edge and } \\
\text { sensor }\end{array}$ & Energy efficient & $\begin{array}{l}\text { Energy-aware scheduling is } \\
\text { yet to be implemented }\end{array}$ \\
\hline
\end{tabular}

which storage and retrieval of big data in an energy efficient manner for wireless sensor networks where the distribution of the node is not uniform [35]. The route-matching approach was used with altitude data by using the cheap and energyefficient air pressure sensors instead of the GPS system for measuring the altitude [36]. The techniques used, benefits, and drawbacks of various research papers for energyefficient data processing for the sensor cloud are given in Table 6.

2.6. Load Balancing Techniques. A novel selection of node strategy reduces the consumption of energy by using the concept of cooperation in which tasks are partitioned optimally and can be executed by the sensors. As a result, computing resources are optimally used [37]. Cloud-assisted monitoring of complex event is used to select the service access point scheme for QoS support under energy-efficient constraint. This approach is reliable, takes less response time, and is energy efficient [38]. A load balancing technique uses the virtual machine approach by which the processing tasks are assigned to the appropriate server, so that the performance is optimized and energy consumption is further reduced [39]. A load balancing strategy for routing, in which the wireless sensor routes the packets, balances the energy consumption of all nodes. So, the network lifetime of the model increases [40]. The benefits, methods used, and drawbacks of various research papers for energy-efficient load balancing techniques for the sensor cloud are given in Table 7.

\section{Analysis}

In this section, we have discussed various parameters used in six categories of techniques. The parameters we have taken into consideration are bandwidth, data size, computational energy, total energy, communication energy, accuracy, reliability, throughput, deadline, availability, network lifetime, packet delivery ratio, data rate, CPU clock frequency, query processing, packet loss, number of hops, response time, total time, storage requirements, scalability, and cost. The parameters used in energy-efficient scheduling techniques for sensor clouds are displayed in Table 8.

According to our classification, eight research papers have used energy-efficient scheduling techniques for the sensor clouds. The parameters which are used in most of the papers for efficient scheduling techniques are total energy, total time, cost, data rate, communication energy, data size, number of hops, CPU clock frequency, and throughput. Accuracy and query processing parameters are not used by any one of the research papers in this scheme. Scalability, storage requirements, response time, and availability parameters are used rarely. Most of the research paper ignores network lifetime and QoS parameters. The parameters used in the energy-efficient sensing techniques for the sensor cloud are displayed in Table 9.

Five research papers have used the energy-efficient sensing techniques. The parameters which are used in most of the papers for energy-efficient sensing techniques are total energy, total time, scalability, and accuracy. Throughput, network lifetime, packet delivery ratio, number of hops, and response time parameters are not used by any of the research paper for these techniques. QoS parameters are not taken into consideration in most of the research papers in these techniques.

The parameters used in energy-efficient data transmission techniques for the sensor cloud are displayed in Table 10. 
TABLE 6: Energy-efficient data processing for the sensor cloud.

\begin{tabular}{|c|c|c|c|c|}
\hline References & Algorithm/method & Problem discussed & Benefit/achievement & Drawback/limitation \\
\hline [33] & $\begin{array}{l}\text { Query management and } \\
\text { optimization }\end{array}$ & $\begin{array}{l}\text { Reduction of the uncertainty } \\
\text { and propagating the query } \\
\text { result intelligently }\end{array}$ & $\begin{array}{l}\text { Reduced energy consumption } \\
\text { and sensing cost }\end{array}$ & $\begin{array}{l}\text { Latency constrained } \\
\text { optimization is yet } \\
\text { to be addressed }\end{array}$ \\
\hline$[34]$ & Integrating WSN and Cloud & $\begin{array}{l}\text { Avoiding network disruption } \\
\text { and loss of data }\end{array}$ & $\begin{array}{l}\text { More network lifetime and } \\
\text { availability of data }\end{array}$ & $\begin{array}{l}\text { Does not support real } \\
\text { time patient monitoring }\end{array}$ \\
\hline [35] & $\begin{array}{c}\text { Storage and retrieval of } \\
\text { big data }\end{array}$ & $\begin{array}{l}\text { To work in an environment } \\
\text { where distribution of the node } \\
\text { is not uniform }\end{array}$ & $\begin{array}{c}\text { Energy efficient, less data loss } \\
\text { rate, } \\
\text { and efficient query processing }\end{array}$ & $\begin{array}{l}\text { Deployment issue in the } \\
\text { real world scenario is } \\
\text { not yet addressed }\end{array}$ \\
\hline$[36]$ & $\begin{array}{l}\text { Routes matching with } \\
\text { altitude data }\end{array}$ & $\begin{array}{c}\text { To use cheap air pressure } \\
\text { sensor } \\
\text { instead of GPS }\end{array}$ & $\begin{array}{l}\text { Increased mobile battery } \\
\text { lifetime }\end{array}$ & $\begin{array}{l}\text { Does not support } \\
\text { multiuser environment }\end{array}$ \\
\hline
\end{tabular}

TABLE 7: Energy-efficient load balancing techniques for the sensor cloud.

\begin{tabular}{|c|c|c|c|c|}
\hline References & Algorithm/method & Problem discussed & Benefit/achievement & Drawback/limitation \\
\hline [37] & $\begin{array}{l}\text { Cooperative node selection } \\
\text { policy }\end{array}$ & Fair use of nodes & Less energy consumption & $\begin{array}{l}\text { Issues related to multihop } \\
\text { transmission with the resource } \\
\text { constraint environment } \\
\text { are not addressed }\end{array}$ \\
\hline$[38]$ & $\begin{array}{l}\text { Selection of access point } \\
\text { scheme }\end{array}$ & $\begin{array}{l}\text { Monitoring of complex } \\
\text { events }\end{array}$ & $\begin{array}{l}\text { Reliable, less response time, good } \\
\text { coverage, and energy efficient }\end{array}$ & $\begin{array}{l}\text { Does not support QoS } \\
\text { related to video processing }\end{array}$ \\
\hline [39] & $\begin{array}{l}\text { Load balancing using } \\
\text { hybrid ant colony } \\
\text { optimization }\end{array}$ & $\begin{array}{l}\text { Dividing tasks and } \\
\text { scheduling }\end{array}$ & $\begin{array}{l}\text { Less time to compute, less end to end } \\
\text { delay, and more network lifetime }\end{array}$ & $\begin{array}{l}\text { Scalability and node failure } \\
\text { issues are not addressed }\end{array}$ \\
\hline [40] & Routing technique & $\begin{array}{l}\text { Balancing the energy } \\
\text { consumption of all } \\
\text { nodes }\end{array}$ & Increased network lifetime & $\begin{array}{l}\text { Does not support scalability } \\
\text { and QoS }\end{array}$ \\
\hline
\end{tabular}

According to our classification, five research papers have used efficient data transmission techniques for the sensor clouds. The parameters which are used in most of the papers for energy-efficient data transmission techniques are total energy, communication energy, data rate, total time, data size, bandwidth, storage requirement, and the number of hops. Computational energy, throughput, query processing, and scalability parameters are not used by any of the papers.

The parameters used in energy-efficient advanced system designing for the sensor cloud are displayed in Table 11.

According to our classification, eight research papers have used the technique of energy-efficient advanced system designing for the sensor clouds. The parameters which are used in most of the papers for energy-efficient advanced system designing techniques are total energy, total time, communication energy, accuracy, packet loss, reliability, and CPU clock frequency. Deadline parameter is not used in any of the research papers. Network lifetime and QoS parameters are not used in most of the research papers. The parameters used in energy-efficient data processing for the sensor cloud are displayed in Table 12.

Four research papers have used energy-efficient data processing for the sensor cloud. The parameters which are used in most of the current papers for energy-efficient data processing are computational energy, total energy, total time, data size, network lifetime, packet loss, and storage requirements. Bandwidth, throughput, delay, and availability parameters are not used in any of the research papers for these techniques. Most of the research papers have not considered QoS parameters.

The parameters used in energy-efficient load balancing techniques for the sensor cloud are displayed in Table 13.

Four research papers have used energy-efficient load balancing techniques for the sensor cloud. The parameters which are used in most of the recent papers for energyefficient load balancing techniques are total energy, total time, and communication energy. Accuracy, CPU clock frequency, query processing, packet loss, number of hops, and scalability parameters are not used in any research papers for these techniques. Most of the research papers ignore QoS parameters.

\section{Discussion}

Various architectures of the energy-efficient sensor cloud in the research papers target many applications such as environmental monitoring, health care services, target tracking, designing the vehicular network, smart homes, agriculture filed, sensing, data analysis, smartphone, complex event monitoring, and task execution. Most of the research papers for an energy efficient sensor-cloud focus on monitoring the environment. Most of the research papers in energy-efficient scheduling techniques do not support 


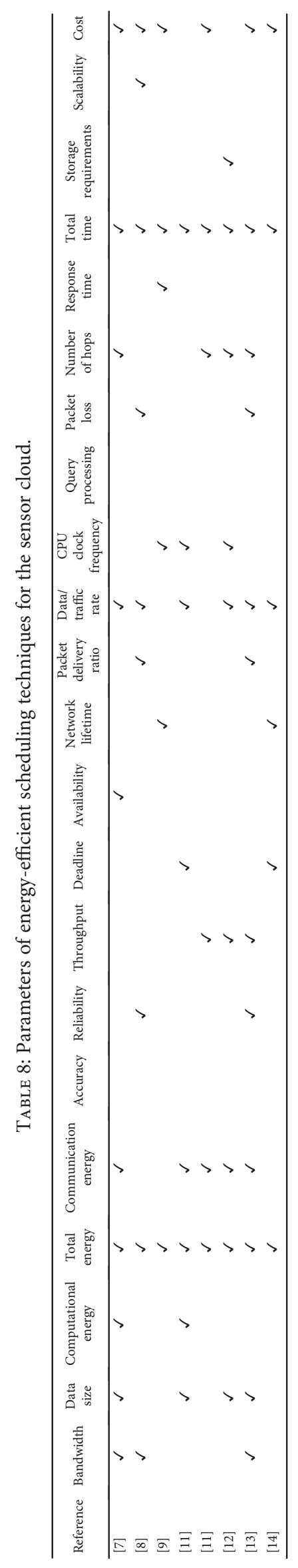




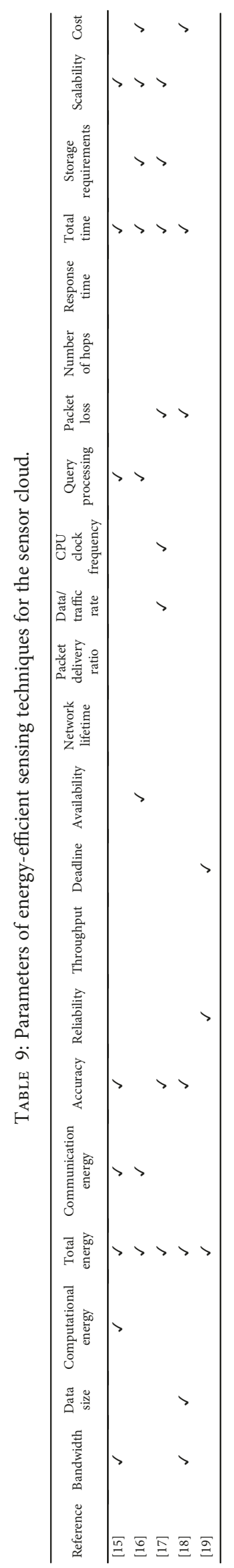




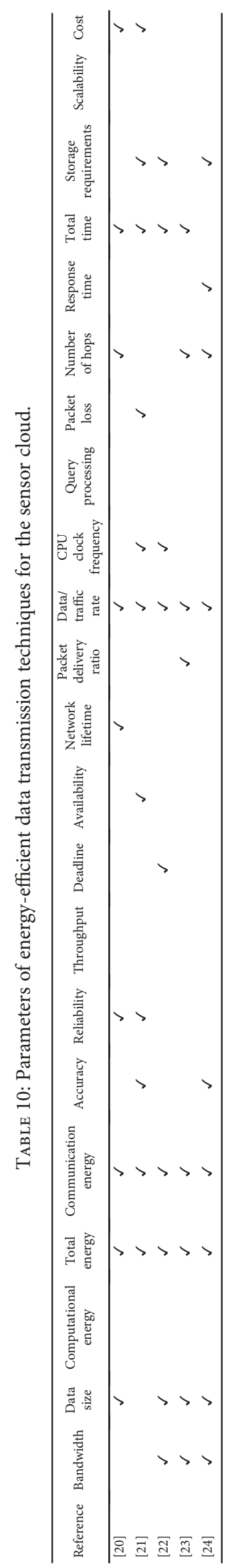




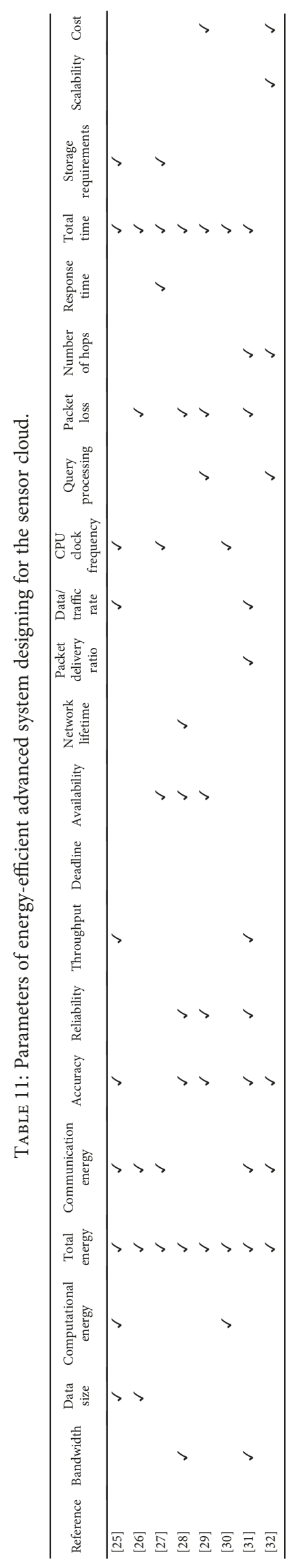




$$
1
$$




$$
1
$$




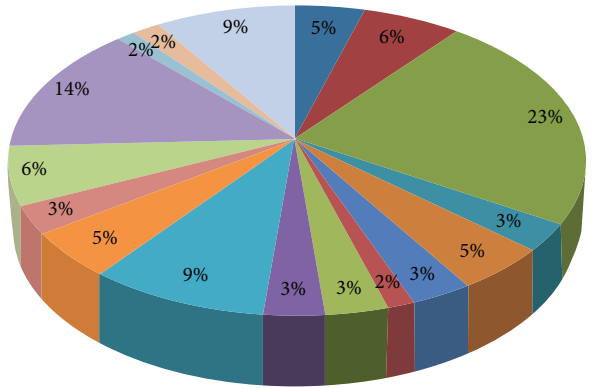

(a)

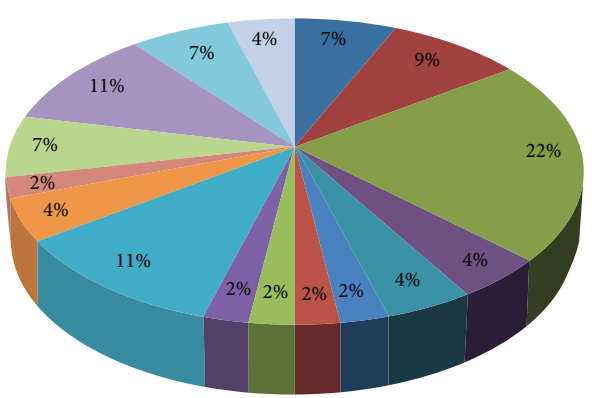

(c)

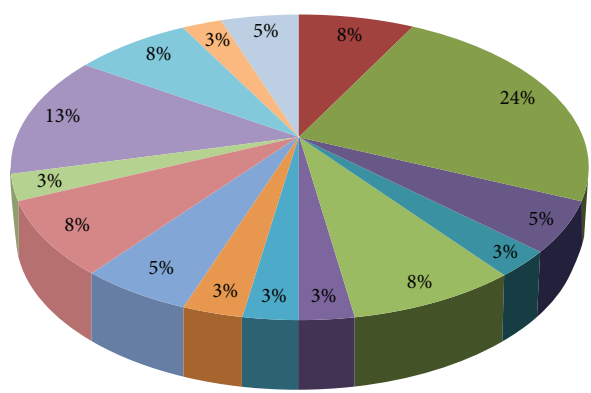

(e)

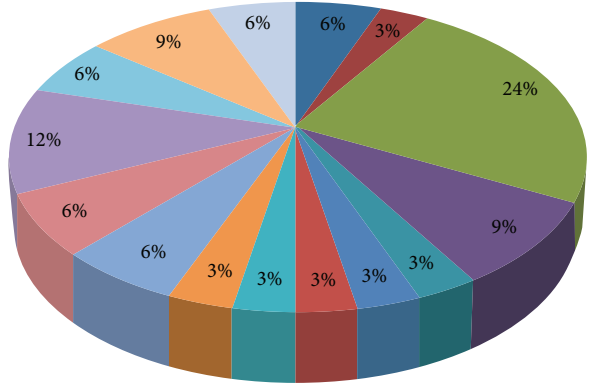

(b)

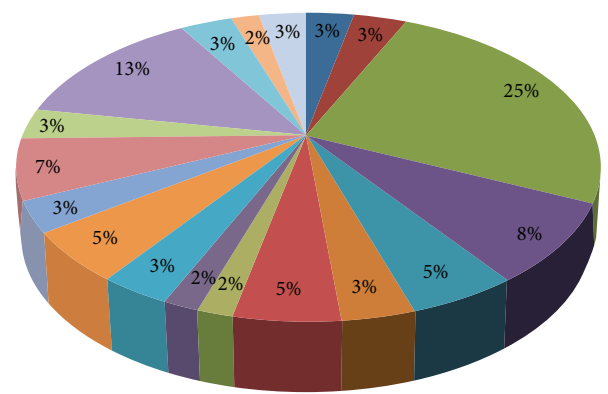

(d)

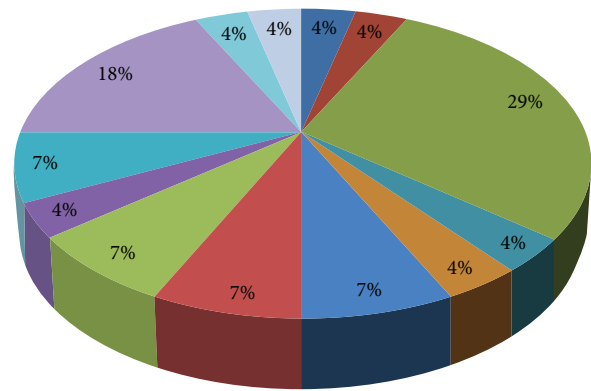

(f)
Bandwidth

Data size

Energy

Accuracy

Reliability

Throughput

Deadline
Availability

Network lifetime

Packet delivery ratio

Data rate

CPU clock frequency

Query processing

Packet loss

Figure 2: Percentage of parameters used in (a) scheduling techniques, (b) sensing techniques, (c) data transmission techniques, (d) advanced system designing, (e) data processing, and (f) load balancing techniques for the energy-efficient sensor cloud.

scalability and also are not suitable for real-time applications. Accuracy, availability, and scalability parameters are ignored in most of the research papers for this technique. The research papers on energy-efficient sensing techniques generally have security-related issues. Throughput, network lifetime, packet delivery ratio, number of hops, and response time parameters are not considered in most of the research papers in this category. Some research papers on energyefficient data transmission techniques ignore multitasking, scalability, mobility, and QoS. Computational energy, 


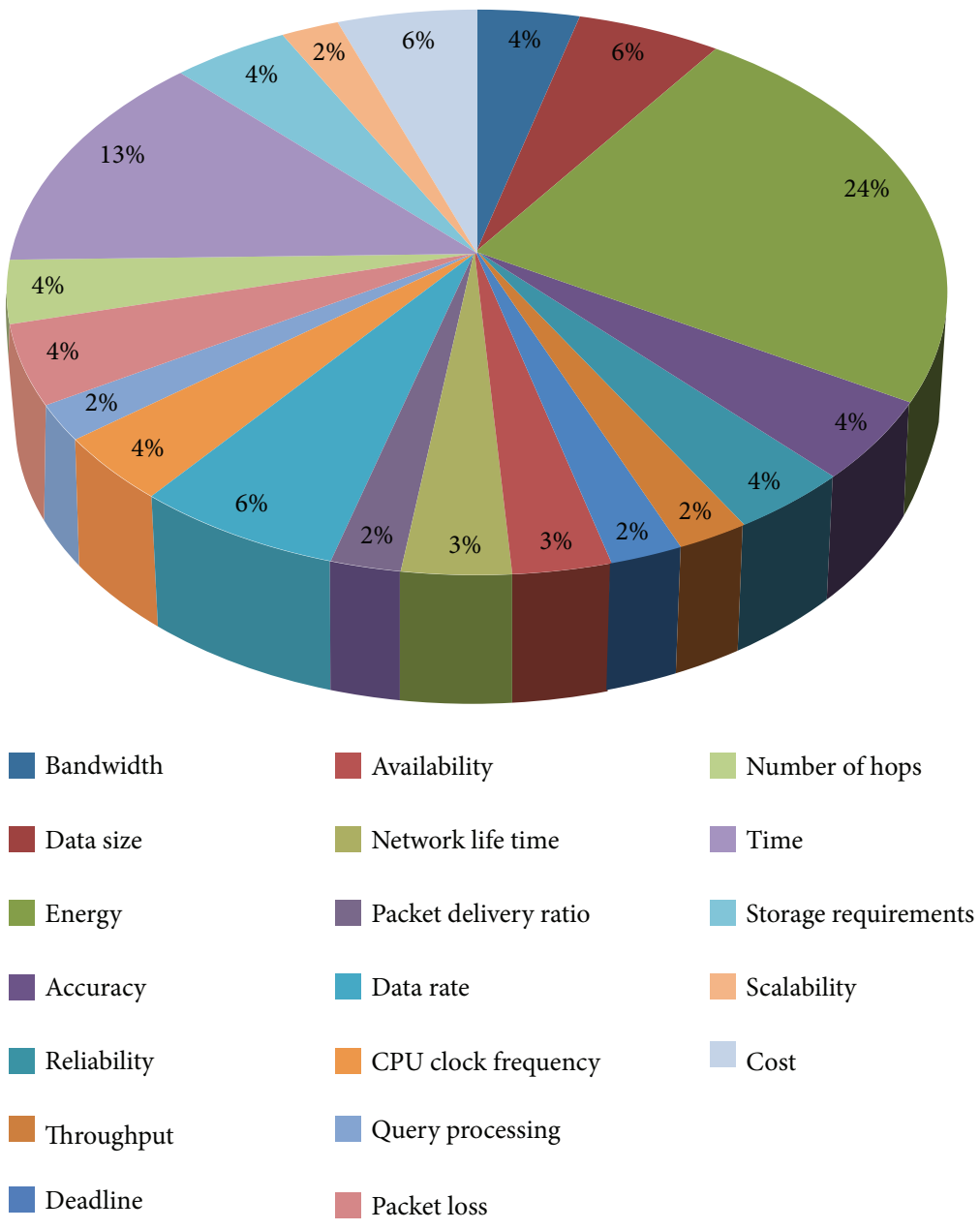

Figure 3: Percentage of parameters used in average for the energy-efficient sensor cloud.

throughput, query processing, and scalability parameters are ignored in most of the research papers for this technique. Some research papers on energy-efficient advanced system designing do not support scalability, QoS, data mining, and data filtering. Deadline, network lifetime, packet delivery ratio, number of hops, response time, and scalability parameters are not considered in most of the research papers in this category. The majority of the research papers on energyefficient data processing do not support real-time applications. Bandwidth, throughput, deadline, and availability are not considered in most of the research papers for this technique. Most of the research papers on energy-efficient load balancing techniques do not support scalability, QoS, and multihop transmission. Accuracy, CPU clock frequency, query processing, packet loss, number of hops, and scalability parameters are not considered in most of the research papers for the abovementioned technique. The parameters we have taken for our analysis are bandwidth, data size, computational energy, total energy, communication energy, accuracy, reliability, throughput, deadline, availability, network lifetime, packet delivery ratio, data rate, CPU clock frequency, query processing, packet loss, number of hops, response time, total time, storage requirements, scalability, and cost. For simplicity, we have combined computational energy, total energy, and communication energy parameters into a single parameter named as energy and we have also combined response time and total time parameters into one parameter named as time. Percentages of parameters used in various energy-efficient techniques are given in Figure 2.

The percentage of the energy parameter used in energyefficient techniques for the sensor cloud ranges from 22 to $29 \%$. Energy parameter is used at $29 \%$ for the load balancing technique whereas for the data transmission technique, it is used only at $22 \%$. Percentages of parameters used on average for energy-efficient sensor-cloud techniques are given in Figure 3.

On an average, energy and time parameters are used 24 and $13 \%$, respectively. Throughput, deadline, packet delivery ratio, query processing, and scalability parameters are used on average of $2 \%$. Availability and network lifetime parameters are used on an average of 3 percent. Bandwidth, accuracy, reliability, CPU clock frequency, packet loss, number of hops, and storage requirement parameters are used 4 percent on an average. Data size, data rate, and cost parameters are used 6 percent on average. Most of the energy-efficient techniques ignore QoS parameters, scalability, network lifetime, and deadline. 


\section{Conclusion}

In this paper, we have made a survey of energy-efficient techniques for the sensor-cloud environment using various parameters. The energy-efficient techniques are classified into six categories according to the techniques used in each research paper. We have taken twenty-two parameters for our analysis. Relatively, the analysis is done by using all twenty-two parameters for all energy-efficient sensor-cloud techniques and we provide the usage percentage of each parameter for every technology. We have also calculated the usage percentage of parameters on average of all technologies we have classified. QoS-related parameters are ignored in most of the energy-efficient techniques for the sensorcloud computing. Many applications such as health care services, environmental monitoring, designing of the vehicular network, smart homes, and complex event monitoring need optimization of energy as well as QoS parameters. Thus, in the future research, QoS-related parameters such as reliability, availability, throughput, deadline, and accuracy must be optimized along with the energy parameter. Multiparameter optimization including QoS parameters along with energy is suggested for the future direction of research.

\section{Conflicts of Interest}

The authors declare no conflicts of interest.

\section{Authors' Contributions}

Kalyan Das and Satyabrata Das have selected various research papers for the survey, classified energy-efficient techniques, and analyzed the parameters used in various research papers according to various categories. Rabi Kumar Darji and Ananya Mishra provide helpful suggestions. All the authors approved the final manuscript.

\section{Acknowledgments}

This work is supported by Sambalpur University Institute of Information Technology, Burla, and Veer Surendra Sai University of Technology, Burla, Odisha, India.

\section{References}

[1] M. Yuriyama and T. Kushida, "Sensor-cloud infrastructure physical sensor management with virtualized sensors on cloud computing," in 2010 13th International Conference on NetworkBased Information Systems (NBiS), pp. 1-8, Takayama, Gifu, Japan, September 2010.

[2] K. Ahmed and M. Gregory, "Integrating wireless sensor networks with cloud computing," in 2011 Seventh International Conference on Mobile Ad-hoc and Sensor Networks (MSN), pp. 364-366, Beijing, China, December 2011.

[3] P. You, H. Li, Y. Peng, and Z. Li, "An integration framework of cloud computing with wireless sensor networks," Lecture Notes in Electrical Engineering, vol. 214, pp. 381387, 2013.

[4] A. Alamri, W. S. Ansari, M. M. Hassan, M. S. Hossain, A. Alelaiwi, and M. A. Hossain, "A survey on sensor-cloud: architecture, applications, and approaches," International Journal of Distributed Sensor Networks, vol. 2013, no. 2, Article ID 917923, 18 pages, 2013.

[5] X. Ma, Y. Cui, and I. Stojmenovic, "Energy efficiency on location based applications in mobile cloud computing: a survey," Procedia Computer Science, vol. 10, pp. 577-584, 2012.

[6] Y. Cui, X. Ma, H. Wang, I. Stojmenovic, and J. Liu, "A survey of energy efficient wireless transmission and modeling in mobile cloud computing," Mobile Networks and Applications, vol. 18, no. 1, pp. 148-155, 2013.

[7] K. Suto, H. Nishiyama, N. Kato, and C. W. Huang, “An energy-efficient and delay-aware wireless computing system for industrial wireless sensor networks," IEEE Access, vol. 3, pp. 1026-1035, 2015.

[8] T. Dinh and Y. Kim, "An efficient interactive model for on-demand sensing-as-a-services of sensor-cloud," Sensors, vol. 16, no. 7, 2016.

[9] R. Dalvi and S. K. Madria, "Energy efficient scheduling of finegranularity tasks in a sensor cloud," in International Conference on Database Systems for Advanced Applications (DASFAA), pp. 498-513, Hanoi, Vietnam, 2015.

[10] W. Zhang, Y. Wen, K. Guan, and D. Kilper, "Energy-optimal mobile cloud computing under stochastic wireless channel," IEEE Transactions on Wireless Communications, vol. 12, no. 9, pp. 4569-4581, 2013.

[11] H.-L. Shi, D. Li, J. F. Qiu, C.-D. Hou, and L. Cui, “A task execution framework for cloud-assisted sensor networks," Journal of Computer Science and Technology, vol. 29, no. 2, pp. 216226, 2014.

[12] S. Sivakumar and A. Al-Anbuky, "Dense clustered multichannel wireless sensor cloud," Journal of Sensor and Actuator Networks, vol. 4, no. 3, pp. 208-225, 2015.

[13] G. Tanganelli, C. Vallati, and E. Mingozzi, "Energy-efficient QoS-aware service allocation for the cloud of things," in 2014 IEEE 6th International Conference on Cloud Computing Technology and Science (CloudCom), pp. 787-792, Singapore, December 2014.

[14] T. Ojha, S. Bera, S. Misra, and N. S. Raghuwanshi, "Dynamic duty scheduling for green sensor-cloud applications," in 2014 IEEE 6th International Conference on Cloud Computing Technology and Science (CloudCom), pp. 841-846, Singapore, December 2014.

[15] S. Sen, A. Misra, R. Balan, and L. Lim, "The case for cloudenabled mobile sensing services," in Proceedings of the First Edition of the MCC Workshop on Mobile Cloud Computing (MCC'12), pp. 53-58, Helsinki, Finland, August 2012.

[16] C. Perera, D. S. Talagala, C. H. Liu, and J. C. Estrella, "Energyefficient location and activity-aware on-demand mobile distributed sensing platform for sensing as a service in IoT clouds," IEEE Transactions on Computational Social Systems, vol. 2, no. 4, pp. 171-181, 2015.

[17] J. Liu, B. Priyantha, T. Hart, H. S. Ramos, A. A. F. Loureiro, and Q. Wang, "Energy efficient GPS sensing with cloud offloading," in Proceedings of the 10th ACM Conference on Embedded Network Sensor Systems (SenSys '12), pp. 85-98, Toronto, ON, Canada, November 2012.

[18] R. Loomba, L. Shi, B. Jennings, R. Friedman, J. Kennedy, and J. Butler, "Energy-aware collaborative sensing for multiple applications in mobile cloud computing," Sustainable Computing: Informatics and Systems, vol. 8, pp. 47-59, 2015. 
[19] X. Sheng, X. Xiao, J. Tang, and G. Xuey, "Sensing as a service: a cloud computing system for mobile phone sensing," in 2012 IEEE Sensors, pp. 1-4, Taipei, Taiwan, October 2012.

[20] S. Chatterjee, S. Sarkar, and S. Misra, "Energy-efficient data transmission in sensor-cloud," in 2015 Applications and Innovations in Mobile Computing (AIMoC), pp. 68-73, Kolkata, India, February 2015.

[21] V. J. Lawson, R. T. Watson, and L. Ramaswamy, "C-SenZ-IS: a customizable sensor IS model for energy efficient SaaS," in 2015 48th Hawaii International Conference on System Sciences (HICSS), pp. 3414-3423, Kauai, HI, USA, January 2015.

[22] C. You, K. Huang, and H. Chae, "Energy efficient mobile cloud computing powered by wireless energy transfer," IEEE Journal on Selected Areas in Communications, vol. 34, no. 5, pp. 17571771, 2016.

[23] D. H. Phan, J. Suzuki, S. Omura, and K. Oba, "Toward sensorcloud integration as a service: optimizing three-tier communication in cloud-integrated sensor networks," in Proceedings of the 8th International Conference on Body Area Networks (BodyNets '13), pp. 355-362, Boston, MA, USA, 2013.

[24] S. S. Grace and M. R. Sumalatha, "SCA - an energy efficient transmission in sensor cloud," in 2014 International Conference on Recent Trends in Information Technology (ICRTIT2014), pp. 1-5, Chennai, India, April 2014.

[25] P. Sathyamoorthy, E. C. H. Ngai, X. Hu, and V. C. M. Leung, "Energy efficiency as an orchestration service for mobile internet of things," in 2015 IEEE 7th International Conference on Cloud Computing Technology and Science (CloudCom), pp. 155-162, Vancouver, BC, Canada, 2015.

[26] S. Samarah, "A data predication model for integrating wireless sensor networks and cloud computing," Procedia Computer Science, vol. 52, pp. 1141-1146, 2015.

[27] N. G. Nair, P. J. Morrow, and G. P. Parr, "Design considerations for a self-managed wireless sensor cloud for emergency response scenario," in 12th Annual PostGraduate Symposium on the Convergence of Telecommunications, Networking and Broadcasting (PGNet 2011), pp. 1-6, Liverpool, UK, March 2011.

[28] L. Skorin-Kapov, K. Pripuzic, M. Marjanovic, A. Antonic, and I. P. Zarko, "Energy efficient and quality-driven continuous sensor management for mobile IoT applications," in Proceedings of the 10th IEEE International Conference on Collaborative Computing: Networking, Applications and Worksharing (CollaborateCom), pp. 397-406, Miami, FL, USA, October 2014.

[29] V. Lawson and L. Ramaswamy, "Data quality and energy management tradeoffs in sensor service clouds," in 2015 IEEE International Congress on Big Data (BigData Congress), pp. 749-752, New York, NY, USA, 2015.

[30] H. Ba, W. Heinzelman, C. A. Janssen, and J. Shi, "Mobile computing - a green computing resource," in 2013 IEEE Wireless Communications and Networking Conference (WCNC), pp. 4451-4456, Shanghai, China, April 2013.

[31] P. Zhang, Z. Yan, and H. Sun, "A novel architecture based on cloud computing for wireless sensor network," in Proceedings of the 2nd International Conference on Computer Science and Electronics Engineering (ICCSEE 2013), pp. 0472-0475, Hangzhou, China, January 2013.

[32] Y. Xu, S. Helal, M. T. Thai, and M. Schmalz, "Optimizing push/pull envelopes for energy-efficient cloud-sensor systems," in Proceedings of the 14th ACM International Conference on Modeling, Analysis and Simulation of Wireless and Mobile Systems (MSWiM '11), pp. 17-26, Miami, FL, USA, 2011.

[33] T. Mo, S. Sen, L. Lim, A. Misra, R. K. Balan, and Y. Lee, "Cloud-based query evaluation for energy-efficient mobile sensing," in 2014 IEEE 15th International Conference on Mobile Data Management (MDM), pp. 221-224, Brisbane, QLD, Australia, July 2014.

[34] R. Piyare and S. R. Lee, “Towards internet of things (IoTs):integration of wireless sensor network to cloud services for data collection and sharing," International Journal of Computer Networks \& Communications, vol. 5, no. 5, pp. 59-72, 2013.

[35] J. Xu, S. Guo, B. Xiao, and J. He, "Energy-efficient big data storage and retrieval for wireless sensor networks with nonuniform node distribution," Concurrency and Computation: Practice and Experience, vol. 27, no. 18, pp. 5765-5779, 2015.

[36] S. Chatterjee, J. K. Nurminen, and M. Siekkinen, "Design of energy-efficient location-based cloud services using cheap sensors," International Journal of Pervasive Computing and Communications, vol. 9, no. 2, pp. 115-138, 2013.

[37] Z. Sheng, C. Mahapatra, V. Leung, M. Chen, and P. Sahu, "Energy efficient cooperative computing in mobile wireless sensor networks," IEEE Transactions on Cloud Computing, vol. PP, no. 99, 2015.

[38] H. Shen, G. Bai, D. Ma, L. Zhao, and Z. Tang, "C2EM: cloudassisted complex event monitoring in wireless multimedia sensor networks," EURASIP Journal on Wireless Communications and Networking, vol. 2015, no. 1, p. 124, 2015.

[39] Y. S. Baviskar, S. C. Patil, and S. B. Govind, "Energy efficient load balancing algorithm in cloud based wireless sensor network," in 2015 International Conference on Information Processing (ICIP), pp. 464-467, Pune, India, December 2015.

[40] S. Zhao and Y. Chen, "Development of cloud computing system based on wireless sensor network protocol and routing," Journal of Chemical and Pharmaceutical Research, vol. 6, no. 7, pp. 1680-1684, 2014. 


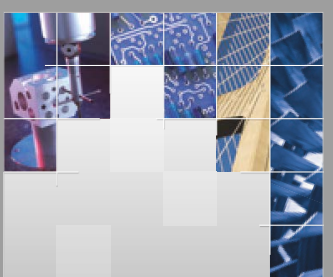

\section{Enfincering}
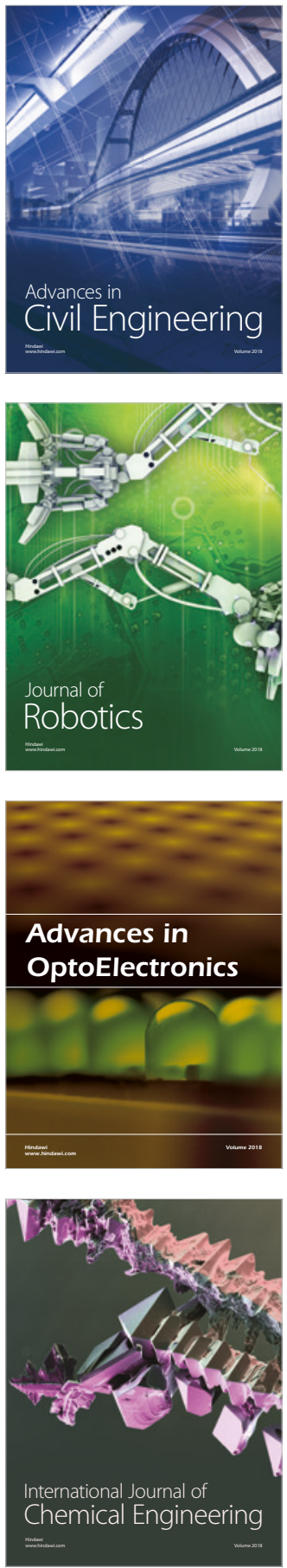

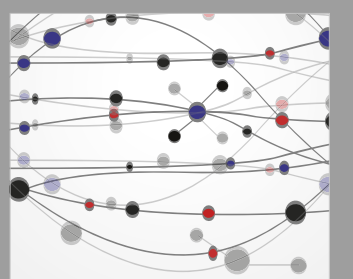

\section{Rotating \\ Machinery}

The Scientific World Journal

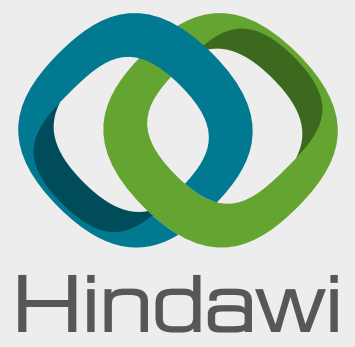

Submit your manuscripts at

www.hindawi.com
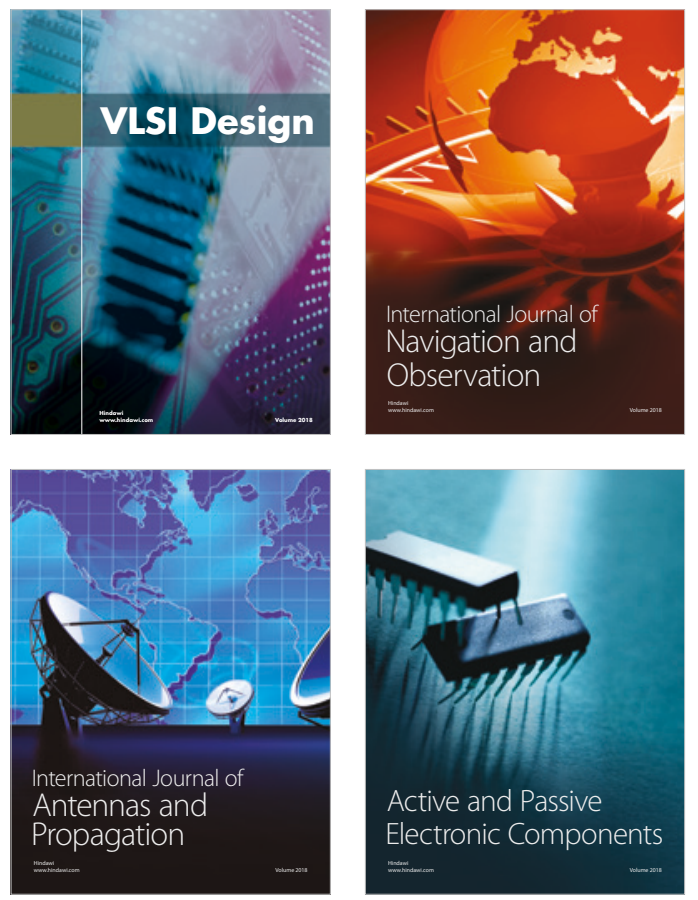
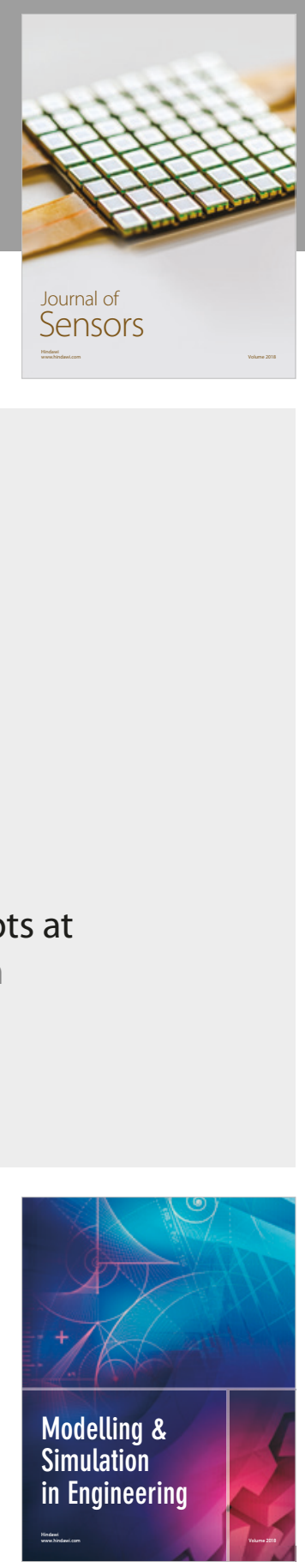

\section{Advances \\ Multimedia}
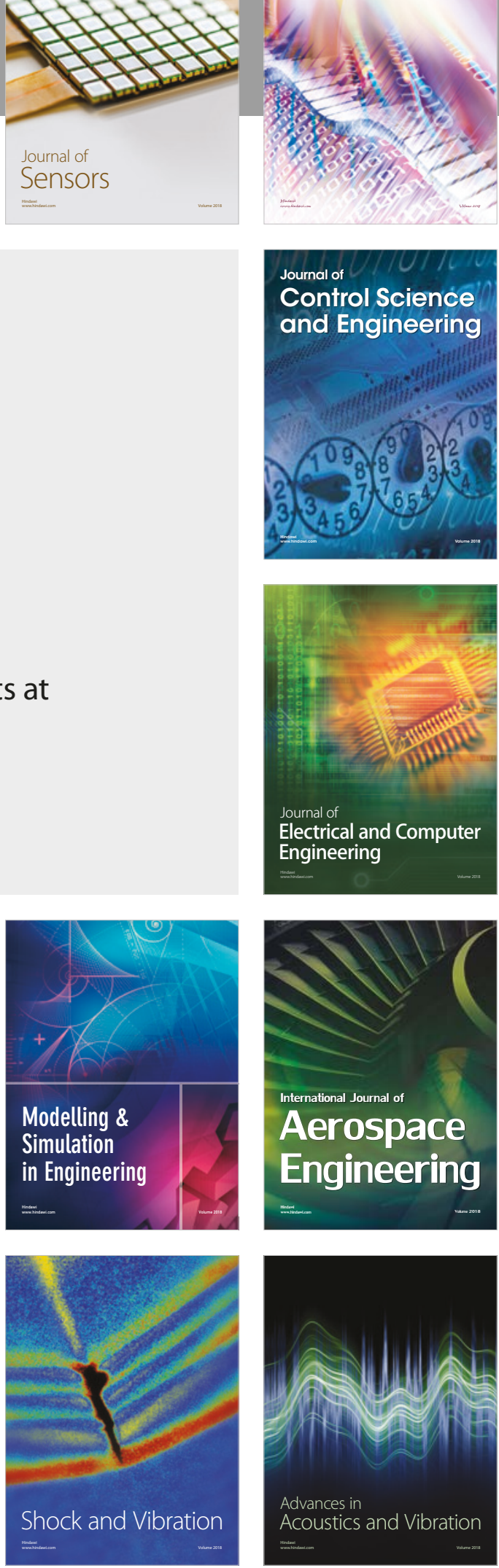